\title{
Physiological roles of taurine in heart and muscle
}

\author{
Stephen W Schaffer ${ }^{1 *}$, Chian Ju Jong ${ }^{1}$, Ramila KC ${ }^{1}$, Junichi Azuma ${ }^{2}$ \\ From $17^{\text {th }}$ International Meeting of Taurine \\ Fort Lauderdale, FL, USA. 14-19 December 2009
}

\begin{abstract}
Taurine (aminoethane sulfonic acid) is an ubiquitous compound, found in very high concentrations in heart and muscle. Although taurine is classified as an amino acid, it does not participate in peptide bond formation. Nonetheless, the amino group of taurine is involved in a number of important conjugation reactions as well as in the scavenging of hypochlorous acid. Because taurine is a fairly inert compound, it is an ideal modulator of basic processes, such as osmotic pressure, cation homeostasis, enzyme activity, receptor regulation, cell development and cell signalling. The present review discusses several physiological functions of taurine. First, the observation that taurine depletion leads to the development of a cardiomyopathy indicates a role for taurine in the maintenance of normal contractile function. Evidence is provided that this function of taurine is mediated by changes in the activity of key $\mathrm{Ca}^{2+}$ transporters and the modulation $\mathrm{Ca}^{2+}$ sensitivity of the myofibrils. Second, in some species, taurine is an established osmoregulator, however, in mammalian heart the osmoregulatory function of taurine has recently been questioned. Third, taurine functions as an indirect regulator of oxidative stress. Although this action of taurine has been widely discussed, its mechanism of action is unclear. A potential mechanism for the antioxidant activity of taurine is discussed. Fourth, taurine stabilizes membranes through direct interactions with phospholipids. However, its inhibition of the enzyme, phospholipid N-methyltransferase, alters the phosphatidylcholine and phosphatidylethanolamine content of membranes, which in turn affects the function of key proteins within the membrane. Finally, taurine serves as a modulator of protein kinases and phosphatases within the cardiomyocyte. The mechanism of this action has not been studied. Taurine is a chemically simple compound, but it has profound effects on cells. This has led to the suggestion that taurine is an essential or semi-essential nutrient for many mammals.
\end{abstract}

\section{Introduction}

Taurine is an ubiquitous sulfur-containing, $\beta$-amino acid, which is considered an essential nutrient in some species [1]. Although it is found in high concentration in most mammalian tissues, its concentration is particularly high in cardiac and skeletal muscle. Lubec et al. [2] have shown that taurine slowly accumulates in the heart following intravenous administration but once taken up by the heart it turns over very slowly. Myocardial taurine content is species dependent, with levels varying from $\sim 1.8 \mu \mathrm{g} / \mathrm{g}$ wet wt in the frog to $\sim 39.4 \mu \mathrm{g} / \mathrm{g}$ wet wt in the mouse [3]. According to Kocsis et al. [3], a correlation exists between taurine levels and heart rate, with the highest taurine levels found in species with the

\footnotetext{
* Correspondence: sschaffe@jaguar1.usouthal.edu

'Department of Pharmacology, University of South Alabama, College of Medicine, Mobile, Alabama 36688, USA

Full list of author information is available at the end of the article
}

highest heart rates. Moreover, a transmural gradient of taurine exists in the left ventricle, with the highest taurine concentrations found in the endocardium, which experiences the greatest work load. Based on this evidence alone Kocsis et al. [3] suggested that taurine might be linked through some mechanism to the workload of the heart.

A considerable body of evidence has been gathered on the pharmacological actions of taurine. These studies have largely focused on the cytoprotective activity of taurine. However, they provide little information on the physiological actions of taurine. Until recently, the physiological actions of taurine were studied using a model of taurine depletion mediated by taurine transport inhibitors or a model of nutritional depletion in cats. Although these studies have uncovered new actions of taurine, in the case of the transport inhibitors it is unclear if the reported actions are related to taurine 
depletion per se or the side effects of the transport inhibitors. The recent development of taurine transporter knockout models has facilitated the study of taurine deficiency in rodents and has dramatically improved the chances of definitively establishing the key physiological functions of taurine. The present review discusses the physiological roles of taurine in heart and skeletal muscle, focusing on the maintenance of contractile function, osmoregulation, conjugation, antioxidant activity, membrane stabilization and protein phosphorylation.

\section{Chemical reactions involving taurine}

Taurine was once considered an end product of sulfur amino acid metabolism, a presumption based on the +4 oxidation state of the sulfur (present as a sulfonic acid moiety). Although it has been suggested that taurine can serve as an antioxidant, the sulfonic acid is incapable of scavenging the common oxidants, namely, superoxide, hydrogen peroxide and hydroxyl radical. Nonetheless, the amino group of taurine can neutralize hypochlorous acid, one of the reactive species generated by neutrophils. In that reaction, taurine is converted to taurine chloramine, which is less toxic than hypochlorous acid and serves as a modulator of the immune system [4]. The amino group of taurine is commonly involved in conjugation reactions. One potentially important reaction is the interaction of taurine with uridine to form 5taurinomethyluridine, a modified base located in the wobble position of some mitochondrial t-RNAs $[5,6]$. This reaction has attracted considerable attention because of its potential involvement in the regulation of mitochondrial protein synthesis $[7,8]$. Other taurineassociated conjugation reactions play central roles in the elimination of toxins from the body [9], the metabolism of lipids (via bile acid conjugation) [10] and the activity of glycolipids [11]. However, the relative chemical inactivity of taurine makes the $\beta$-amino acid attractive as a modulator of basic processes, such as osmotic pressure, cation homeostasis, enzyme activity, receptor regulation, cell development and cell signaling.

\section{Is taurine required for normal contractile function of the heart and muscle?}

Several species, among them cats, dogs and foxes, develop cardiomyopathies when maintained on a taurine deficient diet [12-14]. The original report attributing the development of a cardiomyopathy in cats to taurine deficiency was published in 1987 by Pion et al. [12]. Unlike most dilated cardiomyopathies, Pion et al. [12] found that the taurine deficient cardiomyopathy was reversible, responding favorably to taurine supplementation. Echocardiographic analysis revealed that the taurine deficient cardiomyopathy was characterized by reduced fractional shortening combined with an increase in left ventricular chamber dimensions and impaired response to dobutamine $[15,16]$. Novotny et al. [17] also found decreases in the rate of pressure rise $(+\mathrm{dP} / \mathrm{dt}$, a measure of contractility), reductions in the rate of pressure decline $(-\mathrm{dP} / \mathrm{dt}$, a measure of relaxation) and increases in ventricular chamber compliance in the taurine deficient heart of cats, suggesting that the taurine deficient heart is characterized by defects in both systolic and diastolic function. Also supporting the existence of a taurine deficient cardiomyopathy was the finding that rodents, which can readily synthesize taurine in the liver, develop a taurine deficient cardiomyopathy when the taurine transporter is genetically abolished [18].

Although the mechanism underlying the development of the taurine deficient cardiomyopathy has not been established, it is generally accepted that heart failure is characterized by impaired contraction arising from one or more of the following conditions: (a) diminished handling of calcium by the heart, (b) impaired calcium sensitivity of the contractile proteins, (c) loss of cardiomyocytes and (d) insufficient ATP to drive contraction. Several of these conditions are taurine dependent.

The regulation of calcium homeostasis by taurine has been extensively studied $[19,20]$ although many of the studies examined the effect of extracellular taurine on both contractile function and $\left[\mathrm{Ca}^{2+}\right]_{\mathrm{i}}[21-24]$. Using a skinned fiber preparation containing permeabilized cell membrane, Steele et al. [25] and Galler et al. [26] provided the first evidence that physiological concentrations of taurine can increase $\mathrm{Ca}^{2+}$ sensitivity of contractile proteins and alter tension development. These effects of taurine were attributed to the modulation of sarcoplasmic reticular $\mathrm{Ca}^{2+}$ release, with the effect greater in preparations containing $\mathrm{Ca}^{2+}$ deficient sarcoplasmic reticulum, but less when the sarcoplasmic reticulum contain a high $\mathrm{Ca}^{2+}$ load. In contrast, acute taurine elevations exert no apparent effect on $\mathrm{Ca}^{2+}$ uptake by enriched sarcoplasmic reticular preparations [27-29]. However, the acute taurine studies do not rule out a role of the sarcoplasmic reticular $\mathrm{Ca}^{2+}$ pump in the chronic actions of taurine. Indeed, in vivo chronic taurine influences the activity of the sarcoplasmic reticular $\mathrm{Ca}^{2+}$ ATPase through at least two factors that are altered by taurine. First, recent evidence reveals that the phosphorylation of the sarcoplasmic reticular phosphoprotein, phospholamban is reduced in the taurine deficient heart [30]. Because the phosphorylation of phospholamban enhances the rate of $\mathrm{Ca}^{2+}$ uptake by the sarcoplasmic reticulum, it increases the rate of myocardial relaxation [31]. Second, there is an extensive literature touting the "antioxidant" activity of taurine (see below). According to Park et al. [32] the activity of the sarcoplasmic reticular $\mathrm{Ca}^{2+}$ ATPase is inhibited by oxidative stress. It is known that sarcoplasmic reticular $\mathrm{Ca}^{2+}$ uptake and $\mathrm{Ca}^{2+}$-induced $\mathrm{Ca}^{2+}$ release 
play key roles in regulating $\left[\mathrm{Ca}^{2+}\right]_{\mathrm{i}}$ and modulating $\mathrm{Ca}^{2+}$ delivery and removal from the muscle proteins. Moreover, the binding of $\mathrm{Ca}^{2+}$ to troponin determines the response of the muscle proteins to elevated $\left[\mathrm{Ca}^{2+}\right]_{\mathrm{i}}$. Therefore, it is not surprising that taurine is required for normal systolic and in diastolic function.

Several other factors might also contribute to systolic dysfunction in the taurine deficient heart. It has recently been shown in taurine transporter knockout mice that the phosphorylation of troponin I in the heart is significantly elevated [30]. Because the phosphorylation of troponin I diminishes tension development by interfering with the binding of $\mathrm{Ca}^{2+}$ to troponin $\mathrm{C}$, the taurine deficient heart should generate less ventricular pressure [33]. This conclusion is consistent with the report by Eley et al. [34] showing that taurine deficiency is associated with a decrease in the sensitivity of cardiac muscle to $\mathrm{Ca}^{2+}$. The work of Eley et al. [34] and Lake [35] also show that there is a loss of myofibrils in druginduced taurine deficient hearts, a finding consistent with the notion that taurine deficiency is linked to the loss of cardiomyocytes via apoptosis [36-38].

According to Novotny et al. [15-17] taurine-depleted cats exhibit both systolic dysfunction and a significant increase in left ventricular diastolic chamber compliance. This pattern is characteristic of an eccentric form of hypertrophy, in which the myocytes become thicker and longer than normal. However, in severe cases of eccentric hypertrophy the ventricular chamber dilates and the walls become thinner. Accordingly, the dilated cardiomyopathy phase of eccentric hypertrophy is usually associated with defects in systolic function while the ventricular hypertrophic cardiomyopathy phase is associated with diastolic dysfunction. Therefore, it is reasonable to expect that diastolic defects predominate during the initial stages of the taurine deficient cardiomypathy, while systolic dysfunction predominates in severe cases of the disease. Consistent with this interpretation, Schaffer et al. [36] found that rats treated with the taurine transporter blocker, $\beta$-alanine, only develop a mild diastolic defect characterized by impaired removal of $\mathrm{Ca}^{2+}$ from the cytosol and prolongation of the contractile cycle. In contrast, systolic dysfunction is the dominant defect in life-threatened taurine deficient cats $[12,15,16]$.

Taurine also appears to be essential for normal contraction of skeletal muscle. Warskulat et al. [39] found that skeletal muscle function is severely impaired in taurine transporter knockout mice. Interestingly, physical exercise decreases taurine levels of skeletal muscle, an effect partially prevented by taurine administration [40,41]. Administration of taurine also improves physical endurance. In accordance with the actions of taurine in the heart, Bakker and Berg [42] reported that the effects of taurine are at least partially explained by an augmentation in sarcoplasmic reticular $\mathrm{Ca}^{2+}$ accumulation and release.

\section{Osmoregulatory activity of taurine in heart and muscle}

Cells do not tolerate extreme alterations in cell size, therefore, they possess volume regulatory mechanisms to counteract the consequences of osmotic stress and normalize cell volume. Changes in taurine uptake and release contribute to the normalization of cell volume in most cell types. In the case of heart and muscle the turnover of taurine is normally very slow. Yet myocyte taurine content can be dramatically altered by changes in osmotic stress.

The identification of taurine as an osmoregulator in the heart originated with the work of Vislie and Fugelli [43], who studied the effect of osmotic stress in flounder undergoing a transition from salt to fresh water. Interestingly, they showed that the adaptation of flounder to fresh water was associated with decreases in plasma osmolality, and a corresponding decrease in myocardial taurine content. Although the handling of taurine by the heart was not evaluated by Vislie and Fugelli [43], Rasmusson et al. [44] reported that isolated chick cardiomyocytes exposed to hypoosmotic stress undergo cell swelling, followed by a volume regulatory event that extrudes osmolytes, such as taurine, from the cell.

In contrast to the response to hypoosmotic stress, the regulatory response to hyperosmotic stress leads to increased taurine influx into the cell [45]. In an attempt to explain this phenomenon, Ito et al. [46] examined the promoter region of the taurine transporter for osmotic sensitive elements. They found that the promoter region contains a transcriptional tonicity-responsive element (TonE), which along with the TonE binding protein is involved in the upregulation of the taurine transporter in the hyperosmotically stressed cardiomyocyte.

The osmoregulatory activity of taurine appears to be an important determinant of cell survival. Without specifying the mechanism underlying the cytoprotection, Han and Chesney $[47,48]$ found that upregulation of the taurine transporter significantly reduces the rate of LLC-PK1 cell and renal apoptosis initiated by cisplatin. During the process of apoptosis, apoptotic cells, such as those treated by cisplatin, undergo an exaggerated activation of the regulatory volume decrease in which taurine effluxes the cell. If the regulatory volume decrease is disrupted by preloading the cells with taurine several apoptotic steps, such as DNA fragmentation and apoptotic cell shrinkage, are prevented [50]. Lang et al. [50] found that while taurine loading did not prevent early apoptotic events, such as caspase activation, it blocked the progression of the apoptotic cascade beyond the cell 
shrinkage step. Based on these findings, Ito et al. [51] proposed that Adriamycin-mediated cardiotoxicity might be caused in part by taurine deficiency. Not only does Adriamycin indirectly downregulate the expression of the taurine transporter $[46,51]$, but taurine therapy minimizes the cardiotoxicity of Adriamycin [51,52].

Although taurine loss during apoptotis has an adverse effect on the cell, the loss of taurine during a normal regulatory volume decrease can benefit the hyperosmotically stressed cell by serving as a safety valve to prevent membrane damage caused by excessive cell swelling. This occurs in the ischemic heart, which accumulates osmolytes, such as lactate, phosphate and sodium. Indeed, Allo et al. [53] reported that drug-induced taurine depletion reduces the taurine gradient across the cell membrane of the ischemic heart, a factor that contributes to the observed protection against ischemic injury. Other factors contributing to the observed cytoprotection are alterations in the levels of cationic osmolytes, such as $\mathrm{Na}^{+}$, and activation of cytoprotective protein kinase pathways $[54,55]$.

While osmotic stress affects taurine transport, changes in taurine levels can also affect the transport of other ions through alterations in osmotic stress. One such change occurs during pharmacological elevations in extracellular taurine, which like cell shrinkage, enhances $\mathrm{Na}^{+}-\mathrm{Ca}^{2+}$ exchange activity and elevates $\left[\mathrm{Ca}^{2+}\right]_{i}[56]$. Similarly, elevations in intracellular taurine often mimic osmotic-mediated cell swelling. Among the transporters that are stimulated by both cell swelling and elevations in intracellular taurine are the fast $\mathrm{Na}^{+}$current and $\mathrm{Cl}^{-}$ current [56]. Suleiman et al. [57] attributed the interaction between taurine and $\mathrm{Na}^{+}$movement to the cotransport of taurine and $\mathrm{Na}^{+}$via the taurine transporter. Because hyperosmotic stress promotes the upregulation of the taurine transporter, while a rise in intracellular taurine simultaneously increases the osmotic load and mass action-mediated efflux of taurine and $\mathrm{Na}^{+}$via the taurine transporter, the association between the effects of taurine and certain types of osmotic stress are predictable. In contrast, there is a poor correlation between osmotic-mediated and taurine-mediated changes in $\mathrm{K}^{+}$ current [56].

The link between taurine and $\mathrm{Cl}^{-}$current is intriguing, as the most widely distributed $\mathrm{Cl}^{-}$channel, known as the anion organic osmolyte channel, also conducts taurine [58]. Moreover, a member of the FXYD family of small membrane-spanning proteins, known as phospholemman, forms volume-sensitive channels that conduct anions, such as $\mathrm{Cl}^{-}$, as well as the zwitterion, taurine [59]. Because phospholemman is regulated by protein kinases involved in regulatory volume changes, it has been implicated in cell swelling of cardiomyocytes subjected to hypoosmotic challenges. Indeed, reductions in phospholemman expression decrease taurine efflux in astrocytes [60]. However, cardiomyocytes obtained from phospholemman knockout mice swell to the same extent as wild-type mice in response to a hypoosmotic challenge [61]. Moreover, mouse cardiomyocytes do not undergo a characteristic regulatory volume decrease, raising the possibility that phospholemman may only play a subtle role in volume regulation. Nonetheless, phospholemman is closely tied to transporters involved in osmotic regulation. Jia et al. [62] found that the heart of phospholemman knockout mice exhibit reductions in $\mathrm{Na}^{+}-\mathrm{K}^{+}$ATPase activity and increases in ejection fraction. In contrast, overexpression of phospholemman increases contractility and elevates $\left[\mathrm{Ca}^{2+}\right]_{\mathrm{i}}$, effects attributed to inhibition of the $\mathrm{Na}^{+} / \mathrm{Ca}^{2+}$ exchanger $[63,64]$. Thus, there are still many unresolved questions regarding the role of regulatory volume processes and the osmoregulatory actions of taurine in the heart.

\section{Conjugation reactions of taurine in the heart and skeletal muscle}

Taurine is involved in several conjugation reactions, with the most common reactions occurring in the liver. Nonetheless, one of the most important conjugation reactions takes place in the mitochondria of extrahepatic cells and has a major impact on mitochondrial function $[6,8]$. The formation of 5-taurinomethyl uridine in the anticodon wobble position of mitochondrial tRNA ${ }^{\text {Leu(UUR) }}$ increases UUG translation although the translation of UUA is unaffected [7]. A direct cause-effect relationship between a deficiency in 5-taurinomethyluridine and mitochondrial diseases has been proposed but not definitively established. A major complication is that patients with symptoms of myopathy, encephalopathy, lactic acidosis and stroke-like episodes contain several mutations, only one resulting in a reduction in 5-taurinomethyluridine content [5]. Based on the potential role of 5-taurinomethyluridine in modulating mitochondrial protein synthesis, Schaffer et al. [8] proposed a mechanism for the regulation of reactive oxygen species production by taurine. They predict that diminished rates of 5-taurinomethyluridine arising from taurine deficiency reduce the expression of mitochondrial encoded proteins. Because these proteins are functional subunits of respiratory chain complexes, reduced expression invariably decrease the activity of the complexes. As flux of electrons through the respiratory chain diminishes, there is a risk that electrons will be diverted from the electron transport chain to other acceptors, such as oxygen. The major source of electrons involved in mitochondrial ROS generation comes from complexes 1 and 3 [65]. By elevating the expression of mitochondrial encoded proteins, taurine ensures a smooth coupling between the delivery of reducing equivalents into the electron transport chain, flux of 
reducing equivalents through the respiratory chain and ATP production by oxidative phosphorylation.

\section{Can intracellular taurine provide protection against oxidative stress?}

The literature is awash with studies claiming that taurine is an "antioxidant." Yet Arouma et al. [66] have clearly shown that taurine is incapable of directly scavenging the classical reactive oxygen species (ROS). The only reactive species that is directly neutralized by taurine is $\mathrm{HOCl}$, which is converted to $\mathrm{N}$-chlorotaurine [4]. Because $\mathrm{N}$-chlorotaurine is less toxic than $\mathrm{HOCl}$, the neutralization of $\mathrm{HOCl}$ by taurine might limit myocardial damage caused by neutrophils [4]. This led to the suggestion that the formation of $\mathrm{N}$-chlorotaurine might be the most important antioxidant activity of taurine [67]. However, recent studies have uncovered a key action of taurine could regulate the rate of ROS generation by the mitochondria [8]. This is important because elevated superoxide generation by the mitochondria is capable of initiating the mitochondrial permeability transition, which in turn triggers the apoptotic cascade [68].

Most of the studies that ascribe an antioxidant activity to taurine utilize pharmacological levels of the $\beta$-amino acid to minimize oxidative damage. Only a few studies have examined the potentiation of oxidative damage by taurine depletion. In one such study, Harada et al. [52] showed that drug-induced taurine deficiency potentiates Adriamycin-induced oxidative stress in the heart, an effect thought to exacerbate the cardiotoxicity of Adriamycin. In a related study, Schaffer et al. [69] found that drug-induced taurine deficiency enhances angiotensin II-mediated apoptosis. Although Schaffer et al. [69] did not evaluate the effect of taurine deficiency on angiotensin II-mediated oxidative damage, Ricci et al. [68] recently found that angiotensin II-mediated apoptosis is largely caused by increased oxidative damage within the mitochondria. These two studies revealing an adverse effect of taurine depletion are seemingly at odds with a study that uncovered a beneficial effect of taurine deficiency against ischemia [53]. However, this apparent contradiction merely emphasizes the multifaceted actions of taurine. While the antioxidant activity of taurine might benefit the hypoxic cardiomyocyte, the dominant effects of taurine depletion are diminished $\mathrm{Na}^{+}$and $\mathrm{Ca}^{2+}$ overload and stimulation of the PI 3-kinase/Akt signaling pathway $[54,55,70,71]$.

\section{Role of taurine in membrane stabilization}

In 1973 Huxtable and Bressler [72] found that incubation of isolated sarcoplasmic reticulum with phospholipase $\mathrm{C}$ damaged the membrane, leading to reductions in $\mathrm{Ca}^{2+}$ transport and ATPase activity that were diminished by addition of taurine to the medium. This observation led the authors to propose that taurine acts as a membrane stabilizer. It was subsequently shown that taurine directly interacts with membranes, presumably by forming an electrostatic interaction between the amino and sulfonic acid groups of taurine and the phosphate and amino or quaternary ammonium groups of the phospholipids, respectively [73]. This interaction appears to cause minor changes in the lipid bilayer, allowing more calcium to bind to the phospholipids [74]. However, based on electron spin resonance, neither polymorphic phase changes nor fluidity changes are induced in the lipid bilayer following acute exposure of isolated membranes with taurine. This led to further characterization of the membrane-linked actions of taurine. One of the most prominent taurine-mediated changes in membrane function was found to be the inhibition of phospholipid $\mathrm{N}$-methyltransferase, an enzyme that catalyzes the conversion of phosphatidylethanolamine (PE) to phosphatidylcholine (PC) [75]. This reaction is important because taurine levels regulate the ethanolamine:choline ratio of some membranes [76]. In the biological membrane, PE is preferentially localized to the outer membrane leaflet where it assumes a bilayer structure while PC is a hexagonal former and is preferentially localized to the inner leaflet of the membrane. Thus, changes in the PE/PC ratio have a dramatic influence on the structure of biological membranes, which in turn alters both membrane fluidity and the activity of membrane enzymes and transporters [73].

\section{Are taurine-mediated alterations in protein phosphorylation important physiological functions in heart and skeletal muscle?}

The idea that taurine is capable of altering the phosphorylation of key proteins was initially demonstrated in hearts and retina of taurine treated and drug-induced taurine depleted rats [77]. In the heart, the taurinedependent phosphorylation of a $44 \mathrm{kDa}$ protein is promoted by reductions in taurine levels but diminished by taurine treatment. The effect of taurine depletion on the $44 \mathrm{kDa}$ protein, which was subsequently identified as pyruvate dehydrogenase, is consistent with the metabolic changes mediated by drug-mediated taurine depletion of rat heart [78]. In accordance with the known inhibition of pyruvate dehydrogenase by protein phosphorylation, Mozaffari et al. [78] found that taurine depletion led to a significant elevation of lactate and pyruvate production despite the reduction in pyruvate utilization by the citric acid cycle. The enzyme involved in the phosphorylation of pyruvate dehydrogenase in the taurine deficient heart was not identified, but the response to inhibitors ruled out any involvement of cAMP and cGMP dependent protein kinases [79]. 
Protein kinase $\mathrm{C}$ is also closely related to the osmoregulatory activity of taurine. According to Liu et al. [80] hypoosmotic stress promotes the translocation of selective protein kinase $\mathrm{C}$ isoforms ( $\mathrm{PKC} \alpha, \mathrm{PKC} \varepsilon$, and $\mathrm{PKC} \zeta)$ to specific membranes, an event associated with their activation. Interestingly, taurine treatment also leads to the activation of the same three protein kinase $\mathrm{C}$ isoforms [81]. The activation of these same protein kinase $\mathrm{C}$ isoforms contributes to the osmoregulatory actions of taurine by activating a signaling pathway in which an early event is the stimulation of NADPH oxidase. In the hypoosmotically stressed cell, NADPH oxidase-derived ROS inhibits protein tyrosine phosphatase $1 \mathrm{~B}$, which potentiates swelling-induced taurine release $[82,83]$.

Tyrosine kinases represent another group of protein kinases that are regulated by osmotic stress. Following a hypoosmotic insult, tyrosine kinases activate a downstream target, PI 3-kinase, whose activation stimulates the phosphorylation of Akt [84]. Upregulation of the PI 3-kinase/Akt pathway is cytoprotective, rendering the cell resistant to pathological insults, such as hypoxia, osmotic imbalances, energy deficiency and cationic overload. Drug-induced taurine deficiency also leads to the activation of the PI 3-kinase/Akt pathway, rendering the cell resistant to hypoxia-mediated cell death [54]. Although the beneficial effect of taurine depletion against hypoxic injury has been attributed to diminished accumulation of $\mathrm{Na}^{+}$and $\mathrm{Ca}^{2+}[55,57]$, the stimulation of protein kinase-linked cytoprotective pathways, such as the PI 3-kinase/Akt pathway and PKCE associated cytoprotective pathways, are also likely candidates for the cytoprotection. Because the effects of taurine depletion resemble the potent cytoprotective procedure referred to as ischemic preconditioning $[53,54,71]$, the protein kinase-linked pathways warrant further consideration.

Recent studies reveal that the phosphorylation state of two proteins involved in excitation-contraction coupling is affected by taurine depletion (see section on contractile function). However, the protein kinases affecting these phosphoproteins as well as the importance of these phosphorylation changes in the taurine transporter knockout mice remain to be determined.

\section{Acknowledgements}

This work was supported by a grant from the American Heart Association. This article has been published as part as part of Journal of Biomedical Science Volume 17 Supplement 1, 2010: Proceedings of the 17th International Meeting of Taurine. The full contents of the supplement are available online at http://www.jbiomedsci.com/supplements/17/S1.

\section{Author details}

'Department of Pharmacology, University of South Alabama, College of Medicine, Mobile, Alabama 36688, USA. ${ }^{2}$ Clinical Evaluation of Medicines and Therapeutics, Graduate School of Pharmaceutical Sciences, Osaka University, Osaka 565-0871, Japan
Competing interests

The authors declare that they have no competing interests.

Published: 24 August 2010

\section{References}

1. Knopf K, Sturman JA, Armstrong M, Hayes KC: Taurine: an essential nutrient for the cat. J Nutr 1978, 108:773-778.

2. Lubec B, Ya-hua Z, Pertti S, Pentti T, Kitzmueller E, Lubec G: Distribution and disappearance of the radiolabeled carbon derived from L-arginine and taurine in the mouse. Life Sci 1997, 60:2373-2381.

3. Kocsis JJ, Kostos VJ, Baskin SI: Taurine levels in the heart tissues of various species. Taurine Raven PressHuxtable R, Barbeau A 1976, 145-153.

4. Marcinkiewicz J: Taurine bromamine $(\mathrm{TauBr})$ - its role in immunity and new perspectives for clinical use. J Biomed Sci 17(Suppl 1):S3.

5. Kirino Y, Goto Y-I, Campos Y, Arenas J, Suzuki T: Specific correlation between the wobble modification deficiency in mutant tRNAs and the clinical features of a human mitochondrial disease. Proc Natl Acad Sci USA 2005, 102:7127-7132.

6. Suzuki T, Suzuki T, Wada T, Saigo K, Watanabe K: Taurine as a constituent of mitochondrial tRNAs: new insights into the functions of taurine and human mitochondrial diseases. Embo J 2002, 21:6581-6589.

7. Kirino Y, Yasukawa T, Ohta S, Akira S, Ishihara K, Watanabe K, Suzuki T: Codon-specific translational defect caused by wobble modification deficiency in mutant tRNA from a human mitochondrial disease. Proc Natl Acad Sci USA 2004, 101:15070-15075.

8. Schaffer SW, Azuma J, Mozaffari M: Role of antioxidant activity of taurine in diabetes. Can J Physiol Pharmacol 2009, 87:91-99.

9. Timbrell JA: Principles of Biochemical Toxicology. London and Washington DC: Taylor and Francis 1991.

10. Catafora A, Blotta I, Rossi SS, Hofmann AF, Sturman JA: Dietary taurine content changes liver lipids in cats. J Nutr 1991, 121:1522-1528.

11. Li YT, Maskos K, Chou CW, Cole RB, Li SC: Presence of an unusual GM2 derivative, taurine-conjugated GM2, in Tay-Sachs brain. J Biol Chem 2003, 278:35286-35291.

12. Pion PD, Kittleson MD, Rogers QR, Morris JG: Myocardial failure in cats associated with low plasma taurine: a reversible cardiomyopathy. Science 1987, 237:764-768

13. Kittleson MD, Keene B, Pion PD, Loyer CG: Results of the multicenter spaniel trial (MUST): taurine- and carnitine-responsive dilated cardiomyoathy in American cocker spaniels with decreased plasma taurine concentration. J Vet Intern Med 1997, 11:202-211.

14. Moise NS, Pacioretty LM, Kallfelz FA, Stipanuk MH, King JM, Gilmour RF Jr.: Dietary taurine deficiency and dilated cardiomyopathy in the fox. Am Heart J 1991, 121:541-547.

15. Novotny MJ, Hogan PM, Flannigan G: Echocardiographic evidence for myocardial failure induced by taurine deficiency in domestic cats. Can J Vet Res 1994, 58:6-12

16. Novotny MJ, Hogan PM: Inotropic interventions in the assessment of myocardial failure associated with taurine deficiency in domestic cats. Adv Expt Med Biol 1996, 403:305-314.

17. Novotny MJ, Hogan PA, Paley DM, Adams HR: Systolic and diastolic dysfunction of the left ventricle induced by dietary taurine deficiency in cats. Am J Physiol 1991, 261:H121-H127.

18. Ito T, Kimura Y, Uozumi Y, Takai M, Muraoka S, Matsuda T, Ueki K Yoshiyama M, Ikawa M, Okabe M, Schaffer SW, Fujio Y, Azuma J: Taurine depletion caused by knocking out the taurine transporter gene leads to a cardiomyopathy with cardiac atrophy. J Mol Cell Cardiol 2008, 44:927-937.

19. Satoh $\mathrm{H}$, Sperelakis $\mathrm{N}$ : Review of some actions of taurine on ion channels of cardiac muscle cells and others. Gen Pharmac 1998, 30:451-463.

20. Schaffer SW, Punna S, Duan J, Harada H, Hamaguchi T, Azuma J: Mechanism underlying physiological modulation of myocardial contraction by taurine. Taurine Plenum Press Lombardini J, Schaffer SW Azuma J 1992, 193-198

21. Chovan JP, Kulakowski EC, Sheakowski S, Schaffer SW: Calcium regulation by the low-affinity taurine binding sites of cardiac sarcolemma. $\mathrm{Mol}$ Pharmacol 1980, 17:295-300.

22. Sawamura A, Azuma J, Harada H, Hasegawa H, Ogura K, Sperelakis N Kishimoto S: Protection by oral pretreatment with taurine against the 
negative inotropic effects of low-calcium medium on isolated perfused chick heart. Cardiovasc Res 1983, 17:620-626.

23. Bkaily G, Jaalouk D, Sader S, Shbaklo H, Pothier P, Jacques D, OrleansJuste $P$, Cragoe EJ Jr, Bose R: Taurine indirectly increases $\left[\mathrm{Ca}^{2+}\right]_{1}$ by inducing $\mathrm{Ca}^{2+}$ influx through the $\mathrm{Na}^{+}-\mathrm{Ca}^{2+}$ exchanger. Mol Cell Biochem 1998, 188:187-197.

24. Bkaily G, Jaalouk D, Haddad G, Gros-Louis N, Simaan M, Naik R, Pothier P: Modulation of cytosolic and nuclear $\mathrm{Ca}^{2+}$ and $\mathrm{Na}^{+}$transport by taurine in heart cells. Mol Cell Biochem 1997, 170:1-8.

25. Steele DS, Smith GL, Miller DJ: The effects of taurine on $\mathrm{Ca}^{2+}$ uptake by the sarcoplasmic reticulum and $\mathrm{Ca}^{2+}$ sensitivity of chemically skinned rat heart. J Physiol 1990, 422:499-511.

26. Galler $\mathrm{S}$, Hutzler $\mathrm{C}$, Haller T: Effects of taurine on $\mathrm{Ca}^{2+}$-dependent force development of skinned muscle fibre preparations. J Exp Biol 1990, 152:255-264

27. Entman ML, Bornet EP, Bressler R: The effect of taurine on cardiac sarcoplasmic reticulum. Life Sci 1977, 21:543-550.

28. Remtulla MA, Katz S, Applegarth DA: Effect of taurine on ATP-dependent calcium transport in guinea-pig cardiac muscle. Life Sci 1978, 23:383-390

29. Harada H, Allo S, Viyuoh N, Azuma J, Takahashi K, Schaffer SW: Regulation of calcium transport in drug-induced taurine-depleted hearts. Biochim Biophys Acta 1988, 944:273-278.

30. Schaffer S, KC Ramila, Jong CJ, Ito T, Azuma J: Role of protein phosphorylation in TauTKO cardiomyopathy [abstract]. Int Taurine Symp 2009.

31. Rapundalo ST: Cardiac protein phosphorylation: functional and pathophysiological correlates. Cardiovasc Res 1998, 38:559-588.

32. Park Y, Kanekal S, Kehrer JP: Oxidative changes in hypoxic rat heart tissue. Am J Physiol 1991, 260:H1395-1405.

33. Noland TA Jr, Guo X, Raynor RL, Jideama NM, Averyhart-Fuillard V, Solaro RJ, Kuo JF: Cardiac troponin I mutants: phosphorylation by protein kinases $C$ and $\mathrm{A}$ and regulation of $\mathrm{Ca}^{2+}$ stimulated MgATPase of reconstituted actomyosin S-1. J Biol Chem 1995, 270:25445-25454.

34. Eley DW, Lake N, ter Keurs HEDJ: Taurine depletion and excitationcontraction coupling in rat myocardium. Circ Res 1994, 74:11210-1219.

35. Lake N: Loss of cardiac myofibrils: mechanism of contractile deficits induced by taurine deficiency. Am J Physiol 1993, 264:H1323-H1326.

36. Schaffer S, Solodushko V, Azuma J: Taurine-deficient cardiomyopathy: role of phospholipids, calcium and osmotic stress. Adv Expt Med Biol 2000, 483:57-69.

37. Takatani T, Takahashi K, Uozumi Y, Shikata E, Yamamotot Y, Ito T, Matsuda T, Schaffer SW, Fujio $Y$, Azuma J: Taurine inhibits apoptosis by preventing formation of the Apaf-1/caspase-9 apoptosome. Am J Physiol 2004, 287: C949-C953.

38. Warskulat U, Borsch E, Reinehr R, Heller-Stilb B, Roth C, Witt M, Haeussinger D: Taurine deficiency and apoptosis: findings from the taurine transporter knockout mouse. Arch Biochem Biophys 2007, 462:202-209.

39. Warskulat U, Floegel U, Jacoby C, Hartwig H-G, Thewissen M, Merx MW, Molojavyi A, Heller-Stilb B, Schrader J, Haeussinger D: Taurine transporter knockout depletes muscle taurine levels and results in severe skeletal muscle impairment but leaves cardiac function uncompromised. FASEB $J$ 2004, 18:577-579.

40. Yatabe Y, Miyakawa S, Miyazaki T, Matsuzaki Y, Ochiai N: Effects of taurine administration in rat skeletal muscles on exercise. J Orthop Sci 2003, 8:415-419.

41. Matsuzaki Y, Miyazaki T, Miyakawa S, Bouscarel B, Ikegami T, Tanaka N: Decreased taurine concentration in skeletal muscles after exercise for various durations. Med Sci Sports Exerc 2002, 34:793-797.

42. Bakker AJ, Berg HM: Effect of taurine on sarcoplasmic reticulum function and force in skinned fast-twitch skeletal muscle fibres of the rat. $J$ Physiol 2002, 538:185-194.

43. Vislie T, Fugelli K: Cell volume regulation in flounder (Platichthys flesus) heart muscle accompanying an alteration in plasma osmolality. Comp Biochem Physiol 1975, 52A:415-418.

44. Rasmusson RL, David DG, Lieberman M: Amino acid loss during volume regulatory decrease in cultured chick heart cells. Am J Physiol 1993, 264 C136-C145.

45. Thurston $\mathrm{JH}$, Hauhart RE, Naccarato EF: Taurine: possible role in osmotic regulation of mammalian heart. Science 1981, 214:1373-1374.
46. Ito T, Fujio Y, Schaffer SW, Azuma J: Involvement of transcriptional factor TonEBP in the regulation of the taurine transporter in the cardiomyocyte. Adv Expt Med Biol 2009, 643:523-532.

47. Han X, Chesney RW: TauT protects against cisplatin-induced acute kidney injury (AKI) established in a TauT transgenic mice model. Adv Expt Med Biol 2009, 643:113-122.

48. Han X, Chesney RW: Mechanism of TauT in protecting against cisplatininduced kidney injury (AKI). Adv Expt Med Biol 2009, 643:105-112.

49. Okada Y, Maeno E: Apoptosis, cell volume regulation and volumeregulatory chloride channels. Comp Biochem Physiol Part A 2001, 130:377-383.

50. Lang F, Madlung J, Silemen D, Ellory C, Lepple-Wienhues A, Gulbins E: The involvement of caspases in CD95 (Fas/Apo1) but not swelling-induced cellular taurine release from Jurkat T-lymphocytes. Pfluegers Arch 2000, 440:93-99.

51. Ito T, Muraoka S, Takahashi K, Fujio Y, Schaffer SW, Azuma J: Beneficial effect of taurine treatment against doxorubicin-induced cardiotoxicity in mice. Adv Expt Med Biol 2009, 643:65-73.

52. Harada H, Cusack BJ, Olson RD, Stroo W, Azuma J, Hamaguchi T, Schaffer SW: Taurine deficiency and doxorubicin: interaction with the cardiac sarcolemmal calcium pump. Biochem Pharm 1980, 39:745-751.

53. Allo SN, Bagby L, Schaffer SW: Taurine depletion, a novel mechanism for cardioprotection from regional ischemia. Am J Physiol 1997, 273: H1956-H1961.

54. Pastukh V, Ricci C, Solodushko V, Mozaffari M, Schaffer SW: Contribution of the PI 3-kinase/Akt survival pathway toward osmotic preconditioning. Mol Cell Biochem 2005, 269:59-67.

55. Schaffer SW, Solodushko V, Kakhniashvili D: Beneficial effect of taurine depletion on osmotic sodium and calcium loading during chemical hypoxia. Am J Physiol 2002, 282:C1113-C1120.

56. Schaffer $\mathrm{S}$, Takahashi K, Azuma J: Role of osmoregulation in the actions of taurine. Amino Acids 2000, 19:527-546.

57. Suleiman M-S, Rodrigo GC, Chapman RA: Interdependence of intracellular taurine and sodium in guinea pig heart. Cardiovasc Res 1992, 26:897-905.

58. Stange K, Emma F, Jackson PS: Cellular and molecular physiology of volume-sensitive anion channels. Am J Physiol 1996, 270:C711-C730.

59. Moorman JR, Jones LR: Phospholemman: a cardiac taurine channel involved in regulation of cell volume. Adv Expt Med Biol 1998, 442:219-228.

60. Moran J, Morales-Mulia M, Pasantes-Morales H: Reduction of phospholemman expression decreases osmosensitive taurine efflux in astrocytes. Biochim Biophys Acta 2001, 1538:313-320.

61. Bell JR, Lloyd D, Curl CL, Delbridge LMD, Shattock MJ: Cell volume control in phospholemman (PLM) knockout mice: do cardiac myocytes demonstrate a regulatory volume decrease and is this influenced by deletion of PLM? Exp Physiol 2009, 94:330-343.

62. Jia L-G, Donnet C, Bogaev RC, Blatt RJ, McKinney CE, Day KH, Berr SS, Jones LR, Moorman JR, Sweadner KJ, Tucker AL: Hypertrophy, increased ejection fraction, and reduced Na-K-ATPase activity in phospholemmandeficient mice. Am J Physiol 2005, 288:H1982-1988.

63. Song J, Zhang X-Q, Carl LL, Qureshi A, Rothblum LI, Cheung JY: Overexpression of phospholemman alters contractility and $\left[\mathrm{Ca}^{2+}\right]_{\mathrm{i}}$ transients in adult rat myocytes. Am J Physiol 2002, 283:H576-H583.

64. Zhang X-Q, Qureshi A, Song J, Carl LL, Tian Q, Stahl RC, Carey DJ, Rothblum LI, Cheung JY: Phospholemman modulates $\mathrm{Na} / \mathrm{Ca}$ exchange in adult rat cardiac myocytes. Am J Physiol 2003, 284:H225-233.

65. Turrens JF: Formation of reactive oxygen species in mitochondria. Mitochondria: the dynamic organelle Springer Science and Business MediaSchaffer SW, Suleiman MS 2007, 185-196.

66. Arouma Ol, Halliwell B, Hoey BM, Butler J: The antioxidant action of taurine, hypotaurine and their metabolic precursors. Biochem J 1988, 256:251-255.

67. Schaffer S, Azuma J, Takahashi K, Mozaffari M: Why is taurine cytoprotective? Adv Expt Med Biol 2003, 526:307-321.

68. Ricci C, Pastukh V, Leonard J, Turrens J, Wilson G, Schaffer D, Schaffer SW: Mitochondrial DNA damage triggers mitochondrial superoxide generation and apoptosis. Am J Physiol 2008, 294:C413-C422.

69. Schaffer S, Solodushko V, Pastukh V, Ricci C, Azuja J: Possible cause of taurine deficient cardiomyopathy: potentiation of angiotensin II action. J Cardiovasc Pharmacol 2003, 41:751-759. 
70. Modi P, Suleliman M-S: Myocardial taurine, development and vulnerability to ischemia. Amino Acids 2004, 26:65-70.

71. Murphy E, Steenbergen C: Mechanisms underlying acute protection from cardiac ischemia-reperfusion injury. Physiol Rev 2007, 88:581-609.

72. Huxtable R, Bressler R: Effect of taurine on a muscle intracellular membrane. Biochim Biophys Acta 1973, 323:573-583.

73. Schaffer SW, Azuma J, Matura JD: Mechanisms underlying taurinemediated alterations in membrane function. Amino Acids 1995, 8:231-246.

74. Chovan JP, Kulakowski EC, Benson BW, Schaffer SW: Taurine enhancement of calcium binding to rat heart sarcolemma. Biochim Biophys Acta 1979, 551:129-136.

75. Hamaguchi T, Azuma J, Schaffer SW: Interaction of taurine with methionine: inhibition of myocardial phospholipid methyltransferase. J Cardiovasc Pharmacol 1991, 18:224-230.

76. Huxtable RJ: Physiological actions of taurine. Physiol Rev 1992, 72:101-163.

77. Lombardini JB: Increased phosphorylation of specific rat cardiac and retinal proteins in taurine-depleted animals: isolation and identification of the phosphoproteins. Adv Expt Med Biol 1998, 442:441-447.

78. Mozaffari MS, Tan BH, Lucia MA, Schaffer SW: Effect of drug-induced taurine depletion on cardiac contractility and metabolism. Biochem Pharmacol 1986, 35:985-989.

79. Lombardini JB: The inhibitory effects of taurine on protein phosphorylation: comparison of various characteristics of the taurineaffected phosphoproteins present in rat retina, brain and heart. Adv Expt Med Biol 1994, 359:9-17.

80. Liu X, Zhang Ml, Peterson LB, O'Neil RG: Osmomechanical stress selectively regulates translocation of protein kinase $C$ isoforms. FEBS Lett 2003, 538:101-106.

81. Ito T, Pastukh V, Solodushko V, Azuma J, Schaffer SW: Effect of taurine on protein kinase C isoforms:. Adv Expt Med Biol 2009, 643:3-11.

82. Lambert $\mid \mathrm{H}$ : Reactive oxygen species regulate swelling-induced taurine efflux in NIH3T3 mouse fibroblasts. J Membrane Biol 2003, 192:19-32.

83. Friss MB, Vorum KG, Lambert IH: Volume-sensitive NADPH oxidase activity and taurine efflux in NIH3T3 mouse fibroblasts. Am J Physiol 2008, 294: C1552-C1565.

84. Pasantes-Morales $\mathrm{H}$, Franco R: Influence of protein tyrosine kinases on cell volume change-induced taurine release. Cerebellum 2002, 1:103-109.

doi:10.1186/1423-0127-17-S1-S2

Cite this article as: Schaffer et al:: Physiological roles of taurine in heart and muscle. Journal of Biomedical Science 2010 17(Suppl 1):S2.

\section{Submit your next manuscript to BioMed Central and take full advantage of:}

- Convenient online submission

- Thorough peer review

- No space constraints or color figure charges

- Immediate publication on acceptance

- Inclusion in PubMed, CAS, Scopus and Google Scholar

- Research which is freely available for redistribution

Submit your manuscript at www.biomedcentral.com/submit
Biomed Central 